\title{
Correction to: Enhancement of quality of rainbow trout (Oncorhynchus mykiss) flesh incorporating barley on diet without negative effect on rearing parameters
}

\author{
Julia Pinedo-Gil ${ }^{1}$ - Ana Tomás-Vidal ${ }^{2}$ • \\ Ana María Larrán-García ${ }^{1}$ - Cristina Tomás-Almenar ${ }^{1}$. \\ Miguel Jover-Cerdá ${ }^{2}$ - Miguel Ángel Sanz-Calvo ${ }^{1}$. \\ Ana Belén Martín-Diana ${ }^{1}$
}

Published online: 8 November 2017

(C) Springer International Publishing AG, part of Springer Nature 2017

Correction to: Aquacult Int (2017) 25, 1005-1023

https://doi.org/10.1007/s10499-016-0091-0

The original version of this article unfortunately contained an error in the affiliation section.

The second affiliation should be corrected to Universitat Politècnica de València.

The correct affiliation is shown below.

The online version of the original article can be found at https://doi.org/10.1007/s10499-016-0091-0

Julia Pinedo-Gil

pingilju@gmail.com; Julia.pinedo.gil@gmail.com

1 Subdirection of Research and Technology, Agro-Technological Institute of Castilla y León, Consejería de Agricultura y Ganadería, Finca de Zamadueñas, Ctra. Burgos km. 119, 47171 Valladolid, Spain

2 Research Group of Aquaculture and Biodiversity, Institute of Animal Science and Technology, Universitat Politècnica de València, Camino de Vera, 14, 46071 Valencia, Spain 